\title{
NON-RESPONSE IN THE AMERICAN TIME USE SURVEY: WHO IS MISSING FROM THE DATA AND HOW MUCH DOES IT MATTER?
}

\author{
Katharine G. Abraham \\ Aaron Maitland \\ Suzanne M. Bianchi \\ Technical Working Paper 328 \\ http://www.nber.org/papers/t0328 \\ NATIONAL BUREAU OF ECONOMIC RESEARCH \\ 1050 Massachusetts Avenue \\ Cambridge, MA 02138 \\ September 2006
}

The first draft of this paper was prepared for the American Time Use Survey Early Results Conference, Bethesda, Maryland, December 8-9, 2005. Dorinda Allard and Kristina Shelley of the Bureau of Labor Statistics patiently answered all of our many questions about the data. Mary Edith Bozylinsky provided invaluable assistance in preparing the data for analysis. The authors are grateful for comments on the paper from Michael Brick, Frauke Kreuter, Stanley Presser, Eleanor Singer, Richard Valliant, participants in the ATUS Early Results Conference, and two anonymous reviewers. The views expressed herein are those of the author(s) and do not necessarily reflect the views of the National Bureau of Economic Research.

(C) 2006 by Katharine G. Abraham, Aaron Maitland, and Suzanne M. Bianchi. All rights reserved. Short sections of text, not to exceed two paragraphs, may be quoted without explicit permission provided that full credit, including $(\mathcal{O}$ notice, is given to the source. 
Non-response in the American Time Use Survey: Who Is Missing from the Data and How Much Does It Matter?

Katharine G. Abraham, Aaron Maitland, and Suzanne M. Bianchi

NBER Technical Working Paper No. 328

September 2006

JEL No. J2

\begin{abstract}
This paper examines non-response in a large government survey. The response rate for the American Time Use Survey (ATUS) has been below 60 percent for the first two years of its existence, raising questions about whether the results can be generalized to the target population. The paper begins with an analysis of the types of non-response encountered in the ATUS. We find that non-contact accounts for roughly 60 percent of ATUS non-response, with refusals accounting for roughly 40 percent. Next, we examine two hypotheses about the causes of this non-response. We find little support for the hypothesis that busy people are less likely to respond to the ATUS, but considerable support for the hypothesis that people who are weakly integrated into their communities are less likely to respond, mostly because they are less likely to be contacted. Finally, we compare aggregate estimates of time use calculated using the ATUS base weights without any adjustment for non-response to estimates calculated using the ATUS final weights with a non-response adjustment and to estimates calculated using weights that incorporate our own non-response adjustments based on a propensity model. While there are some modest differences, the three sets of estimates are broadly similar. The paper ends with a discussion of survey design features, their effect on the types and level of non-response, and the tradeoffs associated with different design choices.
\end{abstract}

Katharine G. Abraham

Joint Program in Survey Methodology

1218 LeFrak Hall

University of Maryland

College Park, MD 20742

and NBER

kabraham@survey.umd.edu

Aaron Maitland

Joint Program in Survey Methodology

1218 LeFrak Hall

University of Maryland

College Park, MD 20742

amaitland@ survey.umd.edu
Suzanne M. Bianchi

Department of Sociology

4131 Art-Sociology Building

University of Maryland

College Park, MD 20742

sbianchi@ socy.umd.edu 


\section{Introduction}

The well-documented decline in household survey response rates in recent decades (see, for example, Atrostic et al, 2001, de Leeuw and de Heer, 2002, and Curtin, Presser and Singer, 2005) has lead to growing concern among survey researchers about the quality of household survey data. While government survey response rates have tended to be higher than those for private surveys, even the U.S. federal statistical agencies have experienced increasing difficulty in obtaining household survey interviews. The new American Time Use Survey (ATUS) is a case in point. The ATUS is designed to produce comprehensive information on how Americans use their time, information that, among other potential uses, should deepen our understanding of family life, enrich the analysis of social policy alternatives and support more comprehensive measurement of national output. Despite the survey's official imprimatur, the ATUS response rate has been below 60 percent, and questions naturally have arisen about whether and how the responses obtained can be generalized to the target population.

One feature of the ATUS that facilitates analysis of the causes and consequences of non-response to the survey is the existence of unusually rich information about the ATUS non-respondents. The ATUS sample is drawn from the outgoing rotation groups of the Current Population Survey (CPS). Given their prior participation in the CPS, the process of obtaining responses from those selected for the ATUS sample parallels in certain respects the process of obtaining responses to the follow-on waves of a panel survey. Importantly for our purposes, the information available from the CPS interviews allows us to test competing hypotheses about the reasons for ATUS non-response. 
A starting point for thinking about survey non-response is to consider the different ways in which it may occur. Groves and Couper (1998) develop a model of non-response to household interview surveys that distinguishes non-contact, refusal and other reasons for survey non-response. Lepkowski and Couper (2002) extend this model to longitudinal panel surveys in which specific individuals, rather than specific housing units, are the unit of observation. In their model, non-response in the second and subsequent waves of a panel survey may be the consequence of failure to locate a previously-interviewed sample unit, failure to contact the sample unit once located, or refusal by a sample unit that has been contacted. As emphasized by Groves and Couper (1998), different types of non-response are likely to have different causes and different consequences.

Survey non-response commonly is taken as an indicator of the quality of survey data. In fact, however, non-response is a source of bias in survey estimates only to the extent that those who respond are different from those who do not with respect to the characteristic of interest (Groves, in review). Several recent studies have suggested that there is no consistent relationship between survey response rates and bias in survey estimates (see Curtin, Presser and Singer, 2000; Keeter, et al, 2000; Merkle and Edelman, 2002; and, for a synthesis and review, Groves, in review). This raises the possibility that, in many cases, the money spent on intensive efforts to locate, contact and solicit cooperation from respondents might be better spent on other survey activities. To reach this conclusion for any particular survey, however, requires good evidence on how nonresponse might be affecting the survey estimates. 
Two alternative hypotheses about household survey response seem especially relevant to time diary studies such as the American Time Use Survey (ATUS). One is the hypothesis that people who are busy with other activities are less likely to respond. Being busy could lead both to lower contact rates, since busy people may be less frequently at home, and to higher refusal rates, since busy people may be less willing to take the time to respond to a request for survey participation. If true, this would be a particular problem for a time diary study such as the ATUS, since it is precisely the use of time that such studies are designed to measure, and the under-representation of busy people could seriously distort the estimates produced (see Hochschild, 1989, and Abraham and Mackie, 2005). For example, if people who work long hours are less likely to respond, time diary estimates might understate average hours of work.

An alternative hypothesis is that a person's response propensity reflects strength of social integration, or, put differently, strength of attachment to the broader community. People with weaker community ties may be difficult to locate because they move away, do not have valid phone numbers, and so on, as well as possibly being more difficult to contact because they are less likely to be at home. A person with weak social ties also may be less receptive to completing a survey interview. If people with weak community ties spend their time differently than other people, differences in response propensities associated with the strength of these ties could bias aggregate time use estimates (Robinson and Godbey, 1997 discuss a similar idea). For example, those with weak community attachment may be less likely to engage in volunteer activity, leading to an overstatement of volunteer hours in estimates based on reports from respondents (Abraham, Helms and Presser, 2006). 
There is some evidence in the literature to suggest that busy people may be more difficult to contact for survey interviews. Groves and Couper (1998), for example, report that households in which one would expect at least one adult to be out of the labor force are easier to contact than other households. They also find that those who are difficult to contact spend more hours away from home, but that the same is not true of those who refuse as compared to those who agree to complete an interview once contacted.

The results of several previous papers hint that under-representation of busy people could be a problem for time diary studies specifically. Drago et al. (1999) conducted a pilot time diary study of 58 teachers employed at either a "high stress" school or a different "low stress" school. Teachers at the "high stress" school were much less likely to volunteer to participate in the study. Paakkonen (1999) analyzed data from the nationwide Finnish time diary study conducted in 1987-88. Among 10,574 people contacted for the study, 8,540 participated in an initial short interview. Of these, 7,758 completed a time diary. Those who participated in the initial interview but refused to keep the time diary were no more likely to report feeling "rushed" than those who agreed, but did report working somewhat longer hours.

The results of other studies, however, suggest that busy people may be overrepresented, not underrepresented, in time diary reports. Robinson (1999) examined differences in the distribution of activities reported in the first wave of the 1975 University of Michigan time use survey for those who did and did not participate in the second wave of the same survey. Those who did not respond to the second wave reported in the first wave that they spent less time working and doing housework, but more time sleeping and watching television. Similar results were obtained using data 
from a later time use study conducted in 1985 (Robinson and Godbey, 1997). Knulst and van den Broek (1999) examined rates of response to the several official time diary studies conducted in the Netherlands since 1975 for groups defined on the basis of their age, gender, urbanization of place of residence, position in the family and position in the labor market. The Dutch time use studies required completion of a 7-day diary, and nonresponse rose from about one quarter of the survey sample in 1975 to about three-quarters in 1995. Response rates generally were higher, rather than lower, for those groups in which respondents reported longer hours of paid work and larger total time commitments.

Prior research on household survey non-response that is relevant to the "social integration" hypothesis has proxied the strength of an individual's or a household's community attachment in different ways. A consistent finding in the literature is that household survey response rates are lower for those who live in urbanized areas (Groves, in review). Groves and Couper (1998) report that single-person households, households without children and occupants of multi-unit structures, all of which they characterize as more socially isolated, tend to have lower cooperation rates. In keeping with some earlier research, however, they find no evidence of lower cooperation rates among those who have moved within the past five years. In a study of panel non-response in the Survey of Income and Program Participation (SIPP), Rizzo, Kalton and Brick (1994) find lower response rates for people living in rental housing or in a household headed by someone other than a family member. Similarly, Zabel (1998) reports that, both in the SIPP and in the Panel Study of Income Dynamics, renters are more likely than owners to drop out of the survey from one wave to the next. These analyses do not differentiate, however, between non-contacts and refusals. Lepkowski and Couper (2002) study non-response in 
the second wave of two longitudinal household surveys. Among other results, they find that people who rent rather than own their home are more difficult to locate and, in one of the two surveys they study, also more likely to refuse a survey request. We are not aware of research that has looked specifically at the effects of social integration on response rates in time diary studies.

The plan of the remainder of the paper is as follows. After describing the collection of the ATUS data and our categorization of survey nonresponse, we examine descriptive statistics concerning the disposition of cases included in the ATUS survey sample. Next we explore the bivariate association between sample members' characteristics and the likelihood of responding to the ATUS, looking at indicators of "busyness" and "social integration." We then fit a response propensity model to the data and use the results from this model to adjust survey weights to account for differences in the probability of response associated with a range of individual and household characteristics. The paper concludes with a discussion of the implications of the ATUS nonresponse analysis for understanding and addressing survey non-response more generally, and suggests avenues for further research.

\section{Data and Methods}

The American Time Use Survey (ATUS) is conducted by the U.S. Bureau of the Census with funding from the U.S. Bureau of Labor Statistics (BLS). All ATUS data are collected using computer-assisted telephone interviewing (CATI). The survey was first 
conducted in 2003. The analysis we report is based on ATUS data collected during $2004 .^{1}$

\section{Sample Design}

The target population for the ATUS is the U.S. civilian non-institutionalized population age 15 or older. Individuals chosen for participation in the ATUS are selected randomly from households completing the eighth wave of participation in the Current Population Survey (CPS), the monthly household survey that is the source of official U.S. labor force statistics. The CPS sample over-represents small states; a first stage of selection for the ATUS sample eliminates this over-representation. Households then are stratified by the race/ethnicity of the householder, the presence and age of children in the household, and the number of adults in adult-only households. The rates at which households are sampled for the ATUS differ across these strata. In the third stage of sample selection, one randomly-selected person aged 15 or older in each sampled household is designated for participation in the ATUS. Each sample member is assigned a designated day for which time use information will be collected and telephone interviews are conducted on the day following the designated day. The ATUS diary days are distributed across the days of the week, with 10 percent allocated to each of the weekdays Monday through Friday, 25 percent to Saturdays and 25 percent to Sundays, and distributed evenly across the weeks of the year.

\footnotetext{
${ }^{1}$ In the course of developing our hypotheses regarding the causes and consequences of non-response in the ATUS, we carried out a variety of preliminary analyses using the 2003 data, and did not want to test these hypotheses using the same set of observations. None of our conclusions would have been altered had we used 2003 data.
} 
ATUS interviews generally are conducted between two and four months after the last CPS interview for the ATUS household. If the selected person cannot be contacted on his/her assigned interview date, he/she may be called on the same day the following week. Sample members for whom no telephone number is available (approximately 5 percent of the total) are sent a letter asking that they call the telephone center on a specified day to complete the interview. These respondents are offered an incentive of $\$ 40.00$ for participating in the study. People who have moved away are considered ineligible for participation and dropped from the sample. Efforts to contact an eligible sample member may be continued for up to eight weeks.

People in households that were selected for the CPS but did not complete a waveeight interview have no chance of being selected for the ATUS. Over the recent past, response rates for the eighth-month-in-sample basic CPS questionnaire have averaged about 94 percent. CPS weights that incorporate an adjustment for CPS non-response are used in selecting the ATUS sample and constructing the ATUS estimation weights. Still, to the extent that non-responding CPS households differ from responding households with similar demographic characteristics, there is the potential for bias in the ATUS estimates. Unfortunately, we have no means of assessing any bias from this source and do not consider it further.

\section{Variables}

In analyzing the ATUS, we make use of case disposition information provided on the accompanying survey methodology file. We are especially interested in distinguishing among completed interviews (C), non-contacts (NC), refusals (R) and 
other non-interviews $(\mathrm{O})$. In the ATUS, the interviewer may be unable to contact a designated respondent because that person has moved away or is absent from the household for other reasons; because the interviewer does not have a valid telephone number for the household; or because the designated respondent is never available to speak to the interviewer. The ATUS survey methodology file categorizes designated respondents who have moved away as ineligible (NE), assigns designated respondents who are absent for other reasons such as illness to the "other non-interview" category (O), and considers designated respondents for whom the survey interviewer does not have a valid phone number to be of unknown eligibility (UE). Only those cases for which the validity of a respondent's phone number is established but the interviewer does not succeed in speaking with the respondent are categorized as non-contacts (NC). We consider all of these cases to be non-contacts. ${ }^{2}$ For some purposes, we look separately at non-contact due to the designated respondent having moved away or being absent from the household for other reasons (category NC-1), to bad contact information (NC-2), or to difficulty in finding the designated respondent at home (NC-3). We use the official case disposition codes to identify refusals. ${ }^{3}$ Most of those we categorize as "other noninterviews" $(\mathrm{O})$ are cases involving language barriers. Appendix A displays the detailed case disposition codes recorded on the ATUS survey methodology file, together with the official and our alternate grouping of those codes into broader case disposition categories.

\footnotetext{
${ }^{2}$ Some very small share of those we reassign from the UE and NE categories to the NC category may have joined the Armed Forces or been institutionalized subsequent to their final CPS interview, making them ineligible for the survey. These disqualifying events are so rare, however, that categorizing the groups in question as non-contacts seems most appropriate.

${ }^{3}$ Some "soft" refusals - cases in which a respondent simply avoids ever speaking to the survey interviewer - may be included among those we categorize as non-contacts, but there is no way to identify these "soft" refusals based on the available information.
} 
Beyond the information collected as part of the ATUS interview, additional information about the ATUS sample members and their households is available from the CPS interviews in which they participated. The ATUS-CPS data file provided by the BLS contains most of the information collected as part of the last basic CPS interview for each ATUS household, together with identifiers that allow the ATUS-CPS records to be linked to the ATUS interview records. Importantly for our purposes, the ATUS-CPS file contains records not only for ATUS respondents and the other members of their households, but also for people picked as ATUS respondents who did not complete the survey and the members of their households. A few pieces of information relevant to the analysis of survey non-response - specifically, whether the household rented or owned its housing unit and whether the household was located in a central city - are not included on the ATUS-CPS data file, but were obtained from the relevant CPS basic interview files.

To test our hypotheses about ATUS non-response, we must identify individual and household characteristics that can proxy for "busyness" and "social integration." All else the same, we expect people who work longer hours or have children in the home to be busier. Among those who are married, given own hours of work, people whose spouses work longer hours also may be busier. These observable characteristics admittedly are crude indicators of how busy someone is and how busy people feel may matter more than how busy they actually are, but if "busyness" is important, we would expect to see some association between these proxies and the survey response, contact and cooperation rates. 
A second set of individual and household characteristics proxy for the strength of respondents' social integration into their communities. Many seem likely to be associated with residential stability, which directly affects the probability of non-contact due to not locating a sample member, but also may affect the motivation an individual feels to cooperate in a survey. Married people living with their spouse may be better integrated into their communities than people who are not married. People who are married but separated from their spouse may be more difficult to locate and also less willing to spend time talking to a survey interviewer. ${ }^{4}$ Hours of work may be an indicator of "busyness," but being out of the labor force also could indicate weak social integration. Similarly, the presence of children may affect not only "busyness" but also "social integration." People in households that include children, especially children age 6-17, may be less likely to move and more strongly connected to their communities through their children's schools. Homeowners can be expected to have stronger ties to their communities than renters, and the same may be true of people who live in nonmetropolitan areas. Finally, we have created a variable that captures whether people are living in households that include adults who are not related to the householder, reasoning that such households may tend to be more transient. For completeness, we also have created a variable that captures the presence in the household of other adults who are relatives of the householder.

In addition to the characteristics that relate to either the "busyness" or the "social integration" hypothesis, we consider the ATUS sample member's sex, age, race/ethnicity, household income, education, region and telephone status as potential influences on

\footnotetext{
${ }^{4}$ The married but separated category includes a small number of people who report that they are married but are neither the householder nor the spouse of the householder. We were unable to determine whether these individuals' spouses resided in the same household and assigned them to the separated category.
} 
survey response. ${ }^{5}$ The construction of the individual and household characteristic variables used in our analysis is outlined in Appendix B.

\section{Analysis Plan}

Our analysis begins with simple tabulations of response outcomes for people with different characteristics. We make use of AAPOR response rate RR2:

$$
R R 2=\frac{C}{C+R+N C+O+U E},
$$

where $\mathrm{C}$ represents completed and sufficient partial interviews, $\mathrm{R}$ refusals, NC noncontacts, $\mathrm{O}$ other non-interviews, and UE cases of unknown eligibility (though in fact there are no UE cases in our preferred categorization scheme). We also consider contact rate $\mathrm{CON} 1$ :

$$
C O N 1=\frac{C+R+O}{C+R+N C+O+U E}
$$

and cooperation rate $\mathrm{COOP} 2$ :

$$
C O O P 2=\frac{C}{C+R+O}
$$

Note that the response rate equals the product of the contact rate times the cooperation rate. The non-contact rate is the complement of the contact rate. For some purposes, we are interested in the prevalence of different types of non-contact, as well as in the refusal rate and the other non-interview rate. ${ }^{6}$ All of these survey outcome rates are tabulated by

\footnotetext{
${ }^{5}$ An interesting extension of our analysis might be to consider day-of-week and interactions of day-ofweek with the other variables used in our analysis in explaining response outcomes.

${ }^{6}$ See American Association for Public Opinion Research (2006) for further discussion of various survey outcome rate measures and the relationships among them.
} 
hours worked, by the presence of children in the household, by housing tenure (own versus rent), and so on. ATUS base weights are used for the calculations.

After examining the simple tabulations, we estimate multivariate logistic regressions of the factors that determine response outcome - response, contact, cooperation and so on. The logistic regression for each modeled outcome is estimated independently using weighted data. Standard errors for the estimates from the regressions are estimated using a replicate variance method proposed by Fay (1989) that accounts for the increase in variance associated with the clustering of the ATUS sample relative to the variance that would have been expected for a simple random sample of the same size. ${ }^{7}$

All of the explanatory variables included in the logistic regression models are dichotomous. A dummy variable coefficient that is significant and positive (negative) implies that having the characteristic in question raises (lowers) the probability of the outcome being modeled. The size of these effects on the probability of the modeled outcome, however, depends on the baseline against which the effect is calculated. To assist in interpreting the logistic regression results, we have calculated the implied change in the probability of the outcome of interest associated with having versus not having each specified characteristic, evaluated at the average probability of observing the outcome for the sample as a whole. Rather than reporting the coefficient estimates, we report these marginal probability effects. The statistical significance of the estimated

\footnotetext{
${ }^{7}$ The SAS-callable procedure RLOGIST in SUDAAN, a statistical software package for the analysis of survey data collected using complex sample designs, was used to calculate the standard errors of the logistic regression parameters. The necessary replicate weights were provided by the BLS. Further details are available from the authors upon request.
} 
marginal effects can be determined based on the magnitude and standard errors of the corresponding logistic regression coefficients. ${ }^{8}$

A further question we consider is whether reweighting the data to account for differences in response propensities makes a material difference to estimated patterns of time use. This might be the case if differences in response propensities associated with observable characteristics also have a systematic association with how people use their time. We use the estimated response propensities based on the weighted logistic regression coefficients to calculate non-response adjustment factors equal to the inverse of the estimated response propensity for each survey respondent. ${ }^{9}$

Because different days of the week are represented in different proportions in the survey data and this was not accounted for in the survey base weights, we also make an adjustment to ensure that each day of the week (Sunday through Saturday) received oneseventh of the total of the final survey weights. Our final weight for each respondent thus is equal to:

$$
W_{\text {final }}=W_{\text {base }} x W_{\text {nonresponse }} x W_{\text {day }}
$$

where $\mathrm{W}_{\text {final }}$ is the final weight, $\mathrm{W}_{\text {base }}$ is the ATUS base weight, $\mathrm{W}_{\text {non-response }}$ is the propensity-score-based weight adjustment factor that accounts for differences across observations in their response propensities, and $\mathrm{W}_{\text {day }}$ is the day-of-week adjustment

\footnotetext{
${ }^{8}$ Coefficient estimates from the multivariate models, together with their standard errors, are available from the authors upon request.

${ }^{9}$ As discussed by Little and Vartivarian (2003), an argument can be made for using unweighted rather than weighted logistic regression models as the basis for non-response weight adjustment, but in our case the two models produce very similar coefficient estimates and applying the two sets of weight adjustments yields virtually identical time use estimates.
} 
factor. We compare time use estimates prepared using these weights to unweighted estimates and to estimates produced using the official ATUS estimation weights. ${ }^{10}$

\section{Results}

Our analysis of the ATUS data first examines the distribution of response outcomes, and then considers the personal characteristics associated with different outcomes and how these associations affect the survey estimates.

\section{ATUS response outcomes}

Sample dispositions for the 2004 ATUS are shown in Table 1. The first column in the top panel of the table shows the number of sample members assigned to each major sample disposition category based on the codes from the survey methodology file provided by the BLS; the second column shows the unweighted percentage distribution of these cases for the portion of the sample considered to be eligible respondents; and the third column shows the weighted percentage distribution. The reported figures imply an unweighted (weighted) response rate for the ATUS of 54.6 (56.1) percent. ${ }^{11}$

The bottom panel of Table 1 is similar to the top panel, except that, consistent with our understanding of the AAPOR guidelines, we assign more cases to the noncontact category. The data make clear the importance of problems with contacting

\footnotetext{
${ }^{10}$ The approach we take in this section of the paper is similar to that employed by Rizzo, Kalton and Brick (1994) in their study of panel non-response in the Survey of Income and Program Participation.

${ }^{11}$ The BLS reports an unweighted ATUS response rate 57.3 percent for 2004 . There are two main reasons why the response rate reported by the BLS differs from that we have calculated using the official case disposition codes. First, our rate is based on the set of cases for which a final disposition was obtained during the calendar year in question; the BLS response rate is based on the set of cases initiated during the calendar year and thus cover a slightly different time period. Second, the BLS response rate was calculated prior to editing of the survey data. In 2004, the data collected for several hundred cases were evaluated during editing to be of poor quality, and these cases were recoded from completed interviews to refusals. Working with the edited data thus produces somewhat lower response rates.
} 
respondents as a source of non-response in the 2004 ATUS. Using our classification scheme, non-contact accounts for roughly 60 percent of all survey non-response, with refusals accounting for between 35 and 40 percent and other reasons for the small number remaining. In addition, because the alternative disposition category structure places fewer cases in the not eligible category, the estimated response rate is a bit lower than that obtained using the official ATUS disposition codes.

\section{Bivariate associations}

In Table 2, we tabulate survey outcome rates for the 2004 ATUS. These are shown for the sample as a whole and then broken out separately along various characteristic dimensions. In addition to response, contact and cooperation rates, the table also reports the non-contact rate (both overall and disaggregated by type), the refusal rate, and the other non-interview rate.

The overall non-response rates in Table 2 offer little support for the hypothesis that busy people are less likely to respond to the American Time Use Survey. People who work full-time (35-44 hours a week) have lower response rates than people who work part-time (less than 35 hours a week), but the response rate for people who work more than full time (45 or more hours a week) is comparable to that for people who work part-time, and both are higher than the response rate for people who do not work at all. Among married people, those whose spouses work very long hours have the highest response rates. The presence of children in the household is not strongly related to response propensity. 
The separate components of non-response tell a somewhat different story. Noncontact due to the survey interviewer never being available to talk to the designated respondent (the NC-3 rate) rises monotonically with hours of work, with those who are out of the labor force having the lowest rate and those working very long hours the highest rate. Presence of children does not have a consistent effect on this category of non-contact, however, and none of the "busyness" proxies has an obvious relationship to the refusal rate.

In contrast, there are consistent differences in response rates across groups that conform to the prediction of the "social integration" hypothesis. Response rates are relatively low for people who are out of the labor force, and also for people who are separated or have never been married. Renters' response rates are a full 15 percentage points lower than homeowners' response rates. People identified as living in a central city are approximately 10 percentage points less likely to respond than people living in a non-metropolitan area. People who live in households that include an adult who is not related to the householder are roughly 13 percentage points less likely to respond than people who live in households where everyone is related to the householder. Differences in the incidence of non-contact, especially non-contact related to the respondent being absent from the household or to bad contact information having been recorded for the respondent (NC-1/2), account for most of the response rate differences associated with marital status, housing tenure, urbanicity and household structure.

Looking at the other variables in the table, those who are young, Hispanic or black have significantly lower probabilities of responding to the ATUS; those who are well educated, especially those who have a graduate degree, and those with higher 
household incomes are significantly more likely to respond. These differences are due primarily to variation in contact rates. One exception to this generalization is that the low response rate among people for whom household income is missing is due mostly to their low cooperation rate rather than to a low contact rate. It is perhaps not surprising that people who were unwilling to answer a question about their household income also should be unwilling to answer a battery of questions about how they spend their time.

\section{Multivariate models}

Table 3 summarizes the implied marginal probability effects derived from the multivariate logistic regressions with response outcomes as the dependent variables. To illustrate the interpretation of the estimates reported in the table, the figure shown in the "Widowed" row of the "Non-response" column indicates that, evaluated at the mean probability of non-response, being widowed raises the probability of non-response by an estimated 3.68 percentage points. Statistically significant estimated effects are shown in bold. Like the tabulations reported in Table 2, the multivariate results offer little support for the "busyness" hypothesis. All else the same, part-time workers are less likely to be non-respondents than either those who do not work or those who work longer hours, and married people whose spouse works very long hours have lower non-response probabilities than others. As was also true in the simple tabulations, however, we find that longer hours of work are associated with a higher probability that the respondent will not be available to talk with the interviewer (NC-3).

Something we did not examine in Table 2 was the interaction between marital status and presence of children in the household. The presence of children has no 
significant effect on survey response for married sample members, but the presence of children age 6-17 actually raises the probability of response for unmarried sample members. This finding is at odds with the "busyness" hypothesis, but lends support to the "social integration" hypothesis, insofar as having school-age children can be supposed to engage single parents in their communities.

Most of the "social integration" variables discussed in connection with Table 2 have statistically significant effects in the multivariate non-response model. Response probabilities are significantly lower for renters as compared to homeowners, people who live in metropolitan areas, and people who live in households that include adults not related to the householder. In this model, people who live in households that include other adult relatives of the householder also have lower response rates. Again, most of these differences in response rates reflect differences in the probability of contact.

Other significant control variables in the multivariate models include respondent age (younger people have lower response rates), race (blacks but not Hispanics have lower response rates) and education (those with less education have lower response rates). These differences also reflect primarily differences in contact rates. As before, people who did not report their household income in the CPS have higher refusal rates leading to lower response rates.

\section{Effect of re-weighting on time use estimates}

For each of the people who completed the ATUS interview, the estimated logistic regression coefficients can be used to calculate the probability that a person with that set 
of characteristics would have responded to the survey. ${ }^{12}$ The differences in response propensities across individuals with different characteristics are sizable. Taking the two most extreme examples, the implied response rate for a young black male with less than a high school education who is separated from his spouse; lives in a rented housing unit in a central city in the South; works 35-44 hours per week; resides in a household that includes young children, adult relatives, and adults who are not related to the householder; has no telephone, and did not provide household income information to the CPS interviewer is just 5.1 percent. At the other end of the scale, the implied response rate for a married white female homeowner age 56-65 with a graduate education who lives in a non-metropolitan area in the Midwest; has a telephone; works part-time and has a spouse who works 45 hours or more per week; resides in a household that includes no children or other adults; and has a reported income in the range $\$ 40-75,000$ has an implied response rate of 87.8 percent. As described in the previous section, we calculate a final weight for each survey respondent that incorporates the inverse of their response propensity based on the logistic regression results and a day-of-week adjustment.

The official ATUS estimates reported by the BLS also are calculated using weights that incorporate non-response and day-of-week adjustments. The official weights control the estimated totals from the respondent sample along the dimensions of race, sex, age, presence of children and education. Compared to the official weights, our weights are based on somewhat less detailed age breaks and more detailed education breaks. In addition, we account for all of the other individual and household characteristics shown in Table 3. The official weighting procedures control the day-of-

\footnotetext{
${ }^{12}$ More precisely, the coefficient estimates can be used to calculate the probability that a person with given characteristics would be a non-respondent, and one minus that probability then equals the person's response propensity.
} 
week distribution within each month to the actual representation of days within that month; we adjust the weight totals for the year as a whole so that each day of the week gets one-seventh of the total weight. A final difference is that the official weights control for whether the respondent was offered an incentive to participate, whereas we do not. ${ }^{13}$

In order to see the effect on the ATUS estimates of adjusting for survey nonresponse, and also to learn whether adjusting for differences in non-response related to factors not taken into account in the official weight construction procedures leads to different conclusions about the effects of non-response on the survey estimates, Table 4 reports three different sets of weighted time use estimates based on the 2004 ATUS. The most notable feature of the three sets of estimates is their similarity. Reweighting the data to account for non-response associated with observable characteristics raises the estimates of average time spent sleeping and watching television, and reduces the estimate of average time spent in household chores, but the changes are very small, on the order of 5 minutes per day. Further, the purely demographic adjustments used to produce the official ATUS final weights yield estimates very similar to those based on a more extensive set of personal and household characteristics.

\section{Discussion and Conclusions}

The relatively low ATUS response rate has prompted concern about the potential for bias in the ATUS estimates. Since the inauguration of the ATUS in 2003, the survey response rate consistently has been below 60 percent, with the 2004 response rate

\footnotetext{
${ }^{13}$ Bureau of Labor Statistics and U.S. Census Bureau (2005) provides an overview of how the ATUS weights are constructed and Tupek (2004a, 2004b) gives additional details.
} 
actually slightly below that achieved in 2003. Our study provides new evidence on both the sources and the implications of ATUS non-response.

We document the role of non-contact as opposed to refusals in accounting for the high rate of non-response in a large government survey. According to our estimates, the number of designated respondents who were not contacted by the ATUS interviewers is 50 percent larger than the number who, once contacted, refused to participate in the survey. The response rate to any survey is in part a function of the survey design. Several features of the ATUS design are likely contributors to the high rate of noncontact. First, the choice of the CPS as the ATUS sampling frame creates problems similar to those commonly encountered in panel surveys. Individuals may move during the two to four months that elapse between their final CPS interview and the ATUS interview. In addition, a significant mode switch is made between the CPS and the ATUS. Approximately 20 percent of CPS wave eight interviews are conducted in person, but the ATUS is exclusively a telephone survey. This mode choice makes it more difficult in the ATUS to contact households that do not have a telephone or did not provide a telephone number to the CPS interviewer.

This is not to say that using the CPS as the sampling frame for the ATUS was a poor choice. Selecting the ATUS sample from the outgoing rotations of the CPS significantly reduces ATUS screening costs, and in addition provides a rich set of variables for understanding ATUS non-response patterns and developing post-survey adjustments. These are important considerations in a climate of falling response rates. The CPS has on occasion provided the sampling frame for other surveys, including the 2001 National Survey of Fishing, Hunting, and Wildlife-Associated Recreation (U.S. 
Fish and Wildlife Service, 2002) and the Youth Volunteering and Civic Engagement Survey conducted in 2005 (Corporation for National and Community Service, 2005, 2006). The designers of the Medical Expenditure Panel Survey chose to use the National Health Interview Survey as their sampling frame (Cohen, Machlin and Branscome, 2000). Similar designs may be increasingly attractive to survey researchers in the future. Our point here is simply that there are tradeoffs implicit in this design decision. Making a different choice would present different tradeoffs. For example, the use of an RDD frame would eliminate the loss of sample due to moves, but likely would increase refusals and other types of non-contact. An RDD frame also would provide a poor vector of information about sample members, limiting the options for post-survey adjustments.

A second, though smaller, contributor to the high non-contact rate in the ATUS is the survey's respondent rule. The survey interviewers must speak with one particular individual in the household, rather than accepting a response from whomever they find at home. More restrictive respondent selection rules are well-known to boost non-contact rates (de Leeuw and de Heer, 2002). Further, the designated ATUS respondents must be interviewed on a particular day of the week (e.g., interviewed on Tuesday about their activities on Monday). This also may boost the non-contact rate, though BLS research conducted during the process of designing the ATUS found that allowing day-of-week substitutions across the five weekdays did not significantly affect the overall survey response rate (Frazis et al, 2001).

Non-contact in the ATUS is noteworthy not only because it is so high but also because the personal and household characteristics of those who are contacted differ so systematically from the characteristics of those who are not. Even after controlling for 
demographic characteristics such as age, sex, race and education that are taken into account in standard weighting adjustments, we observe lower contact rates for people whose characteristics suggest weaker ties to the broader community. In contrast to the pattern for non-contacts, refusals are less predictable, with only a very few observable characteristics having any systematic association with the probability of refusing to participate in the survey. The issue of survey non-contact, particularly for people with loose connections to households, is important not just to the ATUS but also to a number of ongoing panel surveys. In addition to being used to construct cross-sectional estimates, data from these surveys are used to track what is happening to individuals over time, and the failure to re-contact respondents in successive waves may be problematic for the analytic usefulness of the data.

As a first step in exploring whether the non-response we observe in the ATUS is a source of bias in the survey estimates, we constructed new weights for the survey that account for differences in response propensities associated with a variety of observable characteristics. Re-weighting the data in this way has relatively little effect on aggregate estimates of time use. Although there are differences in the patterns of time use associated with individuals' observable characteristics and the probability of responding to the ATUS differs with respect to these same characteristics, the net effects on the survey estimates of re-weighting the data to take this into account are not very large.

These findings do not rule out non-response as a source of bias in the ATUS estimates. It is possible that there are differences in the characteristics of respondents and non-respondents for which we have not been able to account, and that these characteristics are strongly associated with how people spend their time. Abraham, 
Helms and Presser (2006) find that people selected for the ATUS sample who reported volunteer activity in the September 2002 CPS Volunteer Supplement were much more likely to respond to the ATUS than people who did not. Estimates of volunteer activity based on the ATUS thus seem very likely to suffer from non-response bias, since the survey sample consists disproportionately of people identified through their CPS responses as active volunteers. Even though the non-response weighting adjustments described in the present paper did not have much effect on the survey estimates we examined, there may be other individual or household characteristics we did not observe that, if taken into account, would make a larger difference, at least for estimates of time devoted to certain activities.

There are several avenues that might be explored in further efforts to better understand the effects of non-response, and especially non-contact, on the ATUS estimates. First, the responses of recent movers - people who entered the CPS sample between the fifth and the eighth survey waves - could be compared to those of people who have not moved recently. Second, it may be possible to use information collected through CPS supplements completed by ATUS sample member households, such as the October school enrollment supplements or the biennial displaced worker supplements, to shed additional light on material differences between ATUS respondents and nonrespondents.

Third, the BLS has made available call history data for all of the cases selected for the 2004 ATUS. If we can assume that designated ATUS respondents who were difficult to contact, based on the number of telephone calls required to reach them or other indicators, are more similar to those who did not respond than are designated respondents 
who were easy to contact, a comparison of the responses received from "difficult" and "easy" respondents could be informative about the direction of non-contact bias in the survey.

The BLS also may wish to consider the collection of additional information to shed light on the potential existence and magnitude of non-response, and especially noncontact, bias in the ATUS. A nonresponse follow-up survey designed to locate and interview those not contacted for the ATUS to learn more about them could be useful. Another strategy might be to add a small number of supplemental questions to the interviews conducted with outgoing CPS rotation group households over several months, again with the goal of obtaining better information about those selected for the ATUS who end up not responding. 


\section{$\underline{\text { References }}$}

Abraham, Katharine G. and Christopher Mackie, eds. 2005. Beyond the Market: Designing Nonmarket Accounts for the United States. Washington, DC: National Academies Press.

Abraham, Katharine G., Sara Helms and Stanley Presser. 2006. "Effects of Survey Nonresponse on Inferences about Volunteer Work." University of Maryland, unpublished manuscript.

American Association for Public Opinion Research. 2006. Standard Definitions: Final Dispositions of Case Codes and Outcome Rates for Surveys. $4^{\text {th }}$ Edition. Lenexa, Kansas: AAPOR.

Atrostic, B.K., Nancy Bates, Geraldine Burt and Adriana Silberstein. 2001. "Nonresponse in U.S. Government Household Surveys: Consistent Measures, Recent Trends, and New Insights." Journal of Official Statistics, 17(2), 209-326.

Cohen, Steven B., Steven R. Machlin, and Jim M. Branscome. 2000. "Patterns of Survey Attrition and Reluctant Response in the 1996 Medical Expenditure Panel Survey," Health Services and Outcomes Research Methodology, 1(2), pp. 131148.

Corporation for National and Community Service. 2005. Building Active Citizens: The Role of Social Institutions in Teen Volunteering. Brief No. 1 in the Youth Helping America series. Washington, DC. November.

Corporation for National and Community Service. 2006. Educating for Active Citizenship: Service-Learning, School-Based Service and Youth Civic

Engagement. Brief No. 2 in the Youth Helping America series. Washington, DC. March.

Curtin, Richard, Stanley Presser and Eleanor Singer. 2000. "Effects of Response Rate Changes on the Index of Consumer Sentiment." Public Opinion Quarterly, 64, pp. 413-428.

Curtin, Richard, Stanley Presser and Eleanor Singer. 2005. "Changes in Telephone Survey Non-response Over the Past Quarter Century." Public Opinion Quarterly, 69(1), pp. 87-98.

De Leeuw, Edith, and Wim de Heer. 2002. “Trends in Household Survey Non-response: A Longitudinal and International Comparison.” In R. Groves, D. Dillman, J. Eltinge and R. Little, eds., Survey Non-response. New York: John Wiley and Sons, 41-54. 
Drago, Robert, et al. 1999. "Time for Surveys: Do Busy People Complete Time Diaries?", Society and Leisure, 21(2), 555-562.

Fay, Robert E. 1989. "Theoretical Application of Weighting for Variance Calculation." Proceedings of the Section on Survey Research Methods of the American Statistical Association, 212-217.

Frazis, Harley, Diane Herz, Karen Piskurich, Lisa Schwartz, and Jay Stewart. 2001. "ATUS Operations and Recommendations Based on 2001 Field Test." Bureau of Labor Statistics. Unpublished presentation materials. September 20.

Groves, Robert M. In review. "Research Synthesis: Non-response Rates and Nonresponse Error in Household Surveys." Public Opinion Quarterly.

Groves, Robert M. and Mick P. Couper. 1998. Non-response in Household Surveys, New York: John Wiley and Sons.

Hochschild, Arlie. 1989. The Second Shift: Working Parents and the Revolution at Home, New York: Viking.

Keeter, S. C. Miller, A. Kohut, R. Groves and S. Presser. 2000. "Consequences of Reducing Non-response in a Large National Telephone Survey." Public Opinion Quarterly, 64, pp. 125-148.

Knulst, Wim, and Andries van den Broek. 1999. "Do Time-Use Surveys Succeed in Measuring 'Busyness': Some Observations of the Dutch Case," Society and Leisure, 21(2), pp. 563-572.

Lepkowski, James and Mick Couper. 2002. "Non-response in the Second Wave of Longitudinal Household Surveys." In R. Groves, D. Dillman, J. Eltinge and R. Little, eds., Survey Non-response. New York: John Wiley and Sons, 259-272.

Little, Roderick J. and Sonya Vartivarian. 2003. "On Weighting the Rates in Nonresponse Weights.” Statistics in Medicine, 22, pp. 1589-99.

Merkle, D. and M. Edelman. 2002. "Non-response in Exit Polls: A Comprehensive Analysis." In R. Groves, D. Dillman, J. Eltinge and R. Little, eds., Survey Nonresponse. New York: John Wiley and Sons, pp. 243-257.

Paakkonen, Hannu. 1999. "Are Busy People Under- or Over-Represented in National Time Budget Surveys," Society and Leisure, 21(2), pp. 573-582.

Rizzo, L., G. Kalton and M. Brick. 1994. Weighting Adjustments for Panel Non-response in the Survey of Income and Program Participation. Working paper, Bureau of the Census, U.S. Department of Commerce. 
Robinson, John P. 1999. “Activity Patterns of Time-Diary Dropouts," Society and Leisure, 21(2), pp. 551-554.

Robinson, John P. and Geoffrey Godbey. 1997. Time for Life: The Surprising Ways that Americans Spend Their Time, University Park, Pennsylvania: Pennsylvania State University

Tupek, Alan R. 2004a. "Revised Weighting Specifications for the American Time Use Survey," Document No. ATUS-06-R, Memorandum to Chester E. Bowie, Demographic Surveys Division, U.S. Census Bureau. October 5.

Tupek, Alan R. 2004b. "Weighting Specifications for the American Time Use Survey for 2004." Document No. ATUS-11. Draft memorandum to Chester E. Bowie. September 30.

U.S. Bureau of Labor Statistics and U.S. Census Bureau. 2005. American Time Use Survey User's Guide: 2003-2004. August.

[http://www.bls.gov/tus/atususersguide.pdf, accessed September 21, 2005.]

U.S. Fish and Wildlife Service. 2002. 2001 National Survey of Fishing, Hunting and Wildlife-Asociated Recreation. FHW/01-NAT. Washington, DC. October.

Zabel, Jeffrey E. 1998. "An Analysis of Attrition in the Panel Study of Income Dynamics and the Survey of Income and Program Participation with an Application to a Model of Labor Market Behavior." Journal of Human Resources, Spring 33(2), pp. 479-506. 
Table 1: Sample Disposition, 2004 American Time Use Survey

\begin{tabular}{lrrr}
\hline Sample Disposition Code & $\begin{array}{r}\text { Unweighted } \\
\text { N }\end{array}$ & $\begin{array}{r}\text { Unweighted } \\
\text { Percent }\end{array}$ & $\begin{array}{r}\text { Weighted } \\
\text { Percent }\end{array}$ \\
\hline Official Category & & & \\
Complete or sufficient partial & 13,973 & 54.6 & 56.1 \\
Refusal & 4,705 & 18.4 & 18.4 \\
Noncontact & 1,827 & 7.1 & 6.5 \\
Other non-interviews & 1,932 & 7.5 & 8.2 \\
Unknown eligibility & 3,175 & 12.4 & 10.9 \\
Total eligible sample & 25,612 & 100.0 & 100.1 \\
$\quad$ Not eligibile & 1,392 & --- & -- \\
Total & 27,004 & --- & --- \\
& & & \\
Regrouped Category & & & \\
(C) Complete or sufficient partial & 13,973 & 52.0 & 53.2 \\
(R) Refusal & 4,705 & 17.5 & 17.5 \\
(NC-1) Contact not attempted & 2,895 & 10.8 & 11.5 \\
(NC-2) Inadequate contact & 3,175 & 11.8 & \\
information & & & 10.3 \\
(NC-3) Unsuccessful contact attempt & 1,827 & 6.8 & 6.2 \\
(O) Other nonresponse & 321 & 1.2 & 1.4 \\
Total eligible sample & 26,896 & 100.0 & 100.1 \\
$\quad$ (NE) Not eligible & 108 & --- & -- \\
Total & 27,004 & --- & -- \\
\hline
\end{tabular}

Note: The NC-1 category in the bottom panel includes 1,284 cases from the "not eligible" category and 1,611 from the "other non-interviews" category in the top panel. The NE and O categories in the bottom panel are the residual portions of the "not eligible" and "other non-interviews" categories in the top panel. All other categories map directly across the panels, though some have different labels. 
Table 2: Distribution of Survey Outcomes by Respondent Characteristics, 2004 American Time Use Survey

\begin{tabular}{|c|c|c|c|c|c|c|c|c|c|c|}
\hline \multirow[b]{3}{*}{ Variable } & \multirow[b]{3}{*}{$\begin{array}{c}\text { Number } \\
\text { in } \\
\text { Sample }\end{array}$} & \multirow[b]{3}{*}{$\begin{array}{l}\text { Response } \\
\text { Rate }\end{array}$} & \multirow{2}{*}{\multicolumn{4}{|c|}{$\begin{array}{l}\text { Contact Status } \\
\text { Noncontact Rates }\end{array}$}} & \multirow[b]{3}{*}{$\begin{array}{l}\text { Number } \\
\text { Contacted }\end{array}$} & \multicolumn{3}{|c|}{ Completion Status } \\
\hline & & & & & & & & \multirow[b]{2}{*}{$\begin{array}{l}\text { Coopera- } \\
\text { tion Rate }\end{array}$} & \multirow[b]{2}{*}{$\begin{array}{l}\text { Refusal } \\
\text { Rate }\end{array}$} & \multirow{2}{*}{$\begin{array}{c}\text { Other } \\
\text { non- } \\
\text { interview } \\
\text { Rate }\end{array}$} \\
\hline & & & $\begin{array}{l}\text { Contact } \\
\text { Rate }\end{array}$ & $\begin{array}{c}\text { Total } \\
\text { Noncontact } \\
\text { Rate }\end{array}$ & $\begin{array}{c}\text { Type 1/2 } \\
\text { Noncontact }\end{array}$ & $\begin{array}{c}\text { Type } 3 \\
\text { Noncontact }\end{array}$ & & & & \\
\hline Total & 26,896 & 53.2 & 72.1 & 27.9 & 21.8 & 6.2 & 18,999 & 73.9 & 24.3 & 1.9 \\
\hline \multicolumn{11}{|c|}{ Respondent's marital status } \\
\hline Separated & 1,389 & 41.0 & 62.3 & 37.7 & 32.7 & 5.0 & 848 & 65.8 & 28.1 & 6.1 \\
\hline Never married & 7,048 & 45.8 & 61.0 & 39.1 & 31.2 & 7.9 & 4,193 & 75.1 & 23.9 & 0.9 \\
\hline \multicolumn{11}{|c|}{ Respondent's hours worked } \\
\hline NILF or unemployed & 10,512 & 52.1 & 72.3 & 27.7 & 23.9 & 3.8 & 7,454 & 72.1 & 25.6 & 2.3 \\
\hline Less than $35 \mathrm{hrs} / \mathrm{wk}$ & 2,388 & 58.5 & 75.6 & 24.4 & 19.0 & 5.4 & 1,784 & 77.3 & 21.7 & 1.0 \\
\hline 35-44 hrs/wk & 9,420 & 51.6 & 70.2 & 29.8 & 21.9 & 7.9 & 6,465 & 73.5 & 24.4 & 2.1 \\
\hline Less than $35 \mathrm{hrs} / \mathrm{wk}$ & 1,110 & 60.3 & 81.3 & 18.7 & 13.2 & 5.5 & 887 & 74.2 & 24.0 & 1.8 \\
\hline 35-44 hrs/wk & 4,774 & 56.7 & 78.4 & 21.6 & 15.1 & 6.5 & 3,678 & 72.3 & 25.5 & 2.2 \\
\hline 45 or more hrs/wk & 2,035 & 65.8 & 82.3 & 17.7 & 12.2 & 5.5 & 1,657 & 80.0 & 19.2 & 0.9 \\
\hline Hours vary & 783 & 58.2 & 81.0 & 19.0 & 13.7 & 5.3 & 625 & 71.9 & 26.3 & 1.8 \\
\hline LF status unknown & 154 & 62.5 & 77.4 & 22.6 & 18.9 & 3.8 & 119 & 80.8 & 18.6 & 0.6 \\
\hline No Spouse & 13,803 & 47.1 & 64.0 & 36.0 & 28.8 & 7.2 & 8,769 & 73.6 & 24.7 & 1.7 \\
\hline \multicolumn{11}{|c|}{ Presence of children age 5 and under } \\
\hline No & 21,813 & 53.5 & 72.7 & 27.3 & 21.3 & 6.0 & 15,551 & 73.5 & 24.7 & 1.8 \\
\hline Yes & 5,083 & 52.0 & 68.5 & 31.5 & 24.4 & 7.1 & 3,448 & 75.9 & 21.8 & 2.3 \\
\hline \multicolumn{11}{|c|}{ Presence of children age 6-17 } \\
\hline No & 17,571 & 53.2 & 71.9 & 28.1 & 21.8 & 6.3 & 12,329 & 73.9 & 24.4 & 1.7 \\
\hline Yes & 9,325 & 53.4 & 72.3 & 27.7 & 21.7 & 6.0 & 6,670 & 73.8 & 24.1 & 2.2 \\
\hline
\end{tabular}


Table 2: Distribution of Survey Outcomes by Respondent Characteristics, 2004 American Time Use Survey (continued)

\begin{tabular}{|c|c|c|c|c|c|c|c|c|c|c|}
\hline \multirow[b]{3}{*}{ Variable } & \multirow[b]{3}{*}{$\begin{array}{l}\text { Number } \\
\text { in } \\
\text { Sample }\end{array}$} & \multirow[b]{3}{*}{$\begin{array}{c}\text { Response } \\
\text { Rate }\end{array}$} & \multicolumn{4}{|c|}{ Contact Status } & \multirow[b]{3}{*}{$\begin{array}{c}\text { Number } \\
\text { Contacted }\end{array}$} & \multicolumn{3}{|c|}{ Completion Status } \\
\hline & & & \multirow[b]{2}{*}{$\begin{array}{c}\text { Contact } \\
\text { Rate }\end{array}$} & \multicolumn{3}{|c|}{ Noncontact Rates } & & \multirow[b]{2}{*}{$\begin{array}{l}\text { Coopera- } \\
\text { tion Rate }\end{array}$} & \multirow[b]{2}{*}{$\begin{array}{c}\text { Refusal } \\
\text { Rate }\end{array}$} & \multirow{2}{*}{$\begin{array}{c}\text { Other } \\
\text { non- } \\
\text { interview } \\
\text { Rate }\end{array}$} \\
\hline & & & & $\begin{array}{c}\text { Total } \\
\text { Noncontact } \\
\text { Rate }\end{array}$ & $\begin{array}{c}\text { Type 1/2 } \\
\text { Noncontact }\end{array}$ & $\begin{array}{c}\text { Type } 3 \\
\text { Noncontact }\end{array}$ & & & & \\
\hline \multicolumn{11}{|l|}{ Housing tenure } \\
\hline Own & 18,612 & 56.9 & 76.8 & 23.2 & 17.6 & 5.5 & 14,202 & 74.0 & 24.7 & 1.3 \\
\hline Rent & 7,971 & 42.5 & 58.4 & 41.7 & 33.7 & 8.0 & 4,579 & 72.8 & 23.1 & 4.2 \\
\hline Not in universe & 313 & 58.5 & 72.2 & 27.8 & 21.5 & 6.4 & 218 & 81.1 & 18.9 & 0.0 \\
\hline \multicolumn{11}{|l|}{ Urbanicity } \\
\hline Central city & 6,637 & 47.6 & 66.2 & 33.8 & 26.6 & 7.2 & 4,294 & 71.8 & 24.3 & 3.9 \\
\hline Balance on MSA & 11,480 & 53.9 & 73.5 & 26.5 & 20.4 & 6.1 & 8,319 & 73.4 & 24.7 & 1.9 \\
\hline Metro-Other & 3,787 & 55.5 & 72.9 & 27.1 & 21.4 & 5.7 & 2,707 & 76.1 & 22.8 & 1.1 \\
\hline Non-metropolitan & 4,938 & 56.8 & 75.3 & 24.7 & 19.5 & 5.3 & 3,637 & 75.5 & 24.2 & 0.3 \\
\hline Not identified & 54 & 58.7 & 80.6 & 19.4 & 14.8 & 4.7 & 42 & 72.9 & 27.1 & 0.0 \\
\hline \multicolumn{11}{|c|}{ Presence of other adults not related to the householder } \\
\hline No & 24,731 & 54.5 & 73.7 & 26.3 & 20.4 & 5.9 & 17,806 & 73.9 & 24.2 & 1.9 \\
\hline Yes & 2,165 & 41.0 & 56.0 & 44.0 & 35.4 & 8.5 & 1,193 & 73.2 & 25.4 & 1.4 \\
\hline \multicolumn{11}{|c|}{ Presence of other adults related to the householder } \\
\hline No & 21,484 & 55.3 & 73.9 & 26.1 & 19.9 & 6.2 & 15,443 & 74.8 & 23.8 & 1.4 \\
\hline Yes & 5,412 & 48.2 & 67.6 & 32.4 & 26.2 & 6.2 & 3,556 & 71.3 & 25.5 & 3.2 \\
\hline \multicolumn{11}{|l|}{ Respondent sex } \\
\hline Male & 12,160 & 51.6 & 70.2 & 29.8 & 23.4 & 6.5 & 8,361 & 73.6 & 24.6 & 1.9 \\
\hline Female & 14,736 & 54.7 & 73.8 & 26.2 & 20.4 & 5.9 & 10,638 & 74.1 & 24.0 & 1.9 \\
\hline \multicolumn{11}{|l|}{ Respondent age } \\
\hline 30 and under & 6,438 & 46.1 & 60.8 & 39.3 & 31.5 & 7.7 & 3,815 & 75.9 & 22.9 & 1.2 \\
\hline $31-45$ & 8,447 & 51.7 & 70.6 & 29.4 & 21.2 & 8.2 & 5,888 & 73.2 & 24.8 & 2.0 \\
\hline $46-55$ & 4,676 & 58.8 & 79.5 & 20.5 & 14.7 & 5.9 & 3,594 & 74.0 & 24.2 & 1.8 \\
\hline $56-65$ & 3,216 & 60.3 & 81.4 & 18.6 & 14.5 & 4.2 & 2,555 & 74.1 & 23.6 & 2.3 \\
\hline Over 65 & 4,119 & 55.3 & 77.1 & 23.0 & 21.2 & 1.7 & 3,147 & 71.7 & 25.9 & 2.4 \\
\hline \multicolumn{11}{|c|}{ Respondent race/ethnicity } \\
\hline Hispanic & 3,508 & 46.4 & 62.1 & 37.9 & 32.4 & 5.5 & 2,127 & 74.7 & 20.5 & 4.7 \\
\hline Non-Hispanic Black & 3,864 & 40.0 & 58.8 & 41.2 & 32.2 & 9.0 & 2,233 & 68.1 & 30.8 & 1.1 \\
\hline Other & 19,524 & 56.1 & 75.4 & 24.6 & 18.7 & 5.9 & 14,639 & 74.4 & 24.1 & 1.6 \\
\hline
\end{tabular}

Table 2: Distribution of Survey Outcomes by Respondent Characteristics, 2004 American Time Use Survey (continued) 
Table 2: Distribution of Survey Outcomes by Respondent Characteristics, 2004 American Time Use Survey (continued)

\begin{tabular}{|c|c|c|c|c|c|c|c|c|c|c|}
\hline \multirow[b]{3}{*}{ Variable } & \multirow[b]{3}{*}{$\begin{array}{l}\text { Number } \\
\text { in } \\
\text { Sample }\end{array}$} & \multirow[b]{3}{*}{$\begin{array}{c}\text { Response } \\
\text { Rate }\end{array}$} & \multicolumn{4}{|c|}{ Contact Status } & \multicolumn{4}{|c|}{ Completion Status } \\
\hline & & & \multirow[b]{2}{*}{$\begin{array}{c}\text { Contact } \\
\text { Rate }\end{array}$} & \multicolumn{3}{|c|}{ Noncontact Rates } & \multirow[b]{2}{*}{$\begin{array}{c}\text { Number } \\
\text { Contacted }\end{array}$} & \multirow[b]{2}{*}{$\begin{array}{l}\text { Coopera- } \\
\text { tion Rate }\end{array}$} & \multirow[b]{2}{*}{$\begin{array}{c}\text { Refusal } \\
\text { Rate }\end{array}$} & \multirow{2}{*}{$\begin{array}{c}\text { Other } \\
\text { non- } \\
\text { interview } \\
\text { Rate }\end{array}$} \\
\hline & & & & $\begin{array}{c}\text { Total } \\
\text { Noncontact } \\
\text { Rate }\end{array}$ & $\begin{array}{c}\text { Type } 1 / 2 \\
\text { Noncontact }\end{array}$ & $\begin{array}{c}\text { Type } 3 \\
\text { Noncontact }\end{array}$ & & & & \\
\hline \multicolumn{11}{|l|}{ Household income } \\
\hline Missing & 5,055 & 41.0 & 68.8 & 31.2 & 25.4 & 5.8 & 3,370 & 59.6 & 37.7 & 2.7 \\
\hline Less than $\$ 20,000$ & 4,947 & 46.2 & 62.5 & 37.5 & 32.1 & 5.5 & 3,043 & 73.9 & 22.5 & 3.6 \\
\hline$\$ 20,000-\$ 39,999$ & 5,817 & 53.9 & 71.0 & 29.0 & 22.7 & 6.3 & 4,087 & 75.9 & 21.8 & 2.3 \\
\hline$\$ 40,000-\$ 74,999$ & 5,982 & 58.8 & 75.6 & 24.4 & 17.4 & 7.0 & 4,483 & 77.7 & 20.8 & 1.5 \\
\hline$\$ 75,000$ or more & 5,095 & 62.0 & 78.5 & 21.5 & 15.5 & 6.0 & 4,016 & 79.0 & 20.7 & 0.4 \\
\hline \multicolumn{11}{|l|}{ Education } \\
\hline Less than high school & 5,225 & 46.9 & 66.3 & 33.7 & 29.3 & 4.4 & 3,370 & 70.7 & 24.9 & 4.5 \\
\hline High school & 8,247 & 48.5 & 69.8 & 30.3 & 23.7 & 6.5 & 5,604 & 69.5 & 28.5 & 2.1 \\
\hline Some college & 6,895 & 54.6 & 72.7 & 27.3 & 20.3 & 7.0 & 4,921 & 75.1 & 24.0 & 0.8 \\
\hline Bachelor's degree & 4,344 & 61.1 & 77.6 & 22.4 & 15.9 & 6.5 & 3,324 & 78.8 & 20.3 & 0.9 \\
\hline Graduate degree & 2,185 & 67.0 & 82.1 & 17.9 & 12.2 & 5.7 & 1,780 & 81.6 & 17.7 & 0.8 \\
\hline \multicolumn{11}{|l|}{ Region } \\
\hline Northeast & 5,312 & 52.4 & 73.1 & 26.9 & 19.9 & 7.0 & 3,828 & 71.7 & 26.0 & 2.4 \\
\hline Midwest & 6,250 & 57.4 & 75.7 & 24.4 & 18.2 & 6.2 & 4,640 & 75.9 & 23.3 & 0.8 \\
\hline South & 9,866 & 50.7 & 68.8 & 31.3 & 25.0 & 6.3 & 6,603 & 73.7 & 25.2 & 1.2 \\
\hline West & 5,468 & 53.7 & 72.7 & 27.3 & 22.1 & 5.2 & 3,928 & 73.8 & 22.6 & 3.6 \\
\hline \multicolumn{11}{|l|}{ Telephone status } \\
\hline Yes & 25,398 & 54.1 & 73.4 & 26.6 & 20.3 & 6.2 & 18,388 & 73.7 & 24.5 & 1.8 \\
\hline No & 1,498 & 35.7 & 44.2 & 55.8 & 51.3 & 4.5 & 611 & 80.6 & 15.9 & 3.6 \\
\hline
\end{tabular}

Note: Standard errors for the estimates are approximately equal to the square root of $1.25^{\star} \mathrm{P}^{*}(100-\mathrm{P}) / \mathrm{N}$, where $\mathrm{P}$ is the estimated rate, $\mathrm{N}$ is the number of observations used in its calculation, and 1.25 is a typical value for the survey design effect in these data. 
Table 3: Marginal Effects on Survey Nonresponse, Noncontact and Refusal Rates, 2004 American Time Use Survey

\begin{tabular}{|c|c|c|c|c|c|}
\hline \multirow[b]{2}{*}{ Predictor } & \multirow[b]{2}{*}{$\begin{array}{l}\text { Non- } \\
\text { response }\end{array}$} & \multicolumn{3}{|c|}{ Noncontact } & \multirow[b]{2}{*}{ Refusals } \\
\hline & & Total & $\begin{array}{l}\text { ypes } \\
1 / 2\end{array}$ & Type 3 & \\
\hline Married householder (yes=1) & -1.01 & -4.16 & -2.63 & -1.65 & $\overline{-0.05}$ \\
\hline Widowed $($ yes $=1$ ) & 3.68 & 4.27 & 2.86 & 2.24 & 0.15 \\
\hline Divorced (yes=1) & 1.27 & 1.86 & -0.27 & 2.17 & 0.65 \\
\hline Spouse absent/ separated (yes $=1$ ) & 7.43 & 2.72 & 4.25 & -1.60 & 3.06 \\
\hline Work less than $35 \mathrm{hrs} / \mathrm{wk}(\mathrm{yes}=1$ ) & -4.39 & -3.31 & -3.44 & 0.49 & -2.32 \\
\hline Work 35-44 hrs/wk (yes=1) & 1.39 & 2.23 & -0.35 & 2.82 & -0.97 \\
\hline Work 45 or more hrs/wk (yes=1) & 1.35 & 3.15 & -0.85 & 4.25 & -1.22 \\
\hline Work hours vary $($ yes $=1)$ & 0.22 & 2.68 & -1.38 & 4.66 & -2.02 \\
\hline Spouse works less than $35 \mathrm{hrs} / \mathrm{wk}($ yes=1) & -1.54 & -3.73 & -3.85 & 0.21 & 1.60 \\
\hline Spouse works $35-44$ hrs/wk (yes=1) & -0.62 & -2.63 & -3.42 & 0.92 & 1.89 \\
\hline Spouse works 45 or more hrs/wk (yes=1) & -5.33 & -3.38 & -3.64 & 0.15 & -3.25 \\
\hline Spouse work hours vary (yes $=1$ ) & -0.18 & -3.43 & -3.29 & -0.02 & 2.78 \\
\hline Spouse labor force status unknown & -8.29 & -5.25 & 0.68 & -2.26 & -3.87 \\
\hline Children under age 6 in household (yes $=1$ ) & 0.86 & 1.92 & -2.58 & 0.82 & -2.50 \\
\hline Children age 6-17 in household (yes=1) & -6.98 & -5.85 & -3.37 & -2.00 & -2.29 \\
\hline Married $^{*}$ Children under age 6 (yes $=1$ ) & -2.57 & -1.23 & 0.73 & -1.03 & 0.20 \\
\hline Married $^{*}$ Children age 6-17 (yes-1) & 7.36 & 5.65 & 3.92 & 1.87 & 3.18 \\
\hline Renter (yes $=1$ ) & 8.13 & 10.22 & 9.03 & 1.19 & -1.32 \\
\hline Central city resident (yes $=1$ ) & 6.79 & 4.62 & 3.44 & 1.25 & 1.49 \\
\hline Balance of MSA resident (yes $=1$ ) & 4.60 & 2.96 & 2.42 & 0.61 & 1.60 \\
\hline Other metropolitan area resident (yes $=1$ ) & 1.34 & 1.44 & 1.46 & 0.02 & -0.65 \\
\hline Adult non-relatives in household (yes-1) & 7.94 & 7.12 & 7.46 & -0.39 & 2.57 \\
\hline Adult relatives in household (yes-1) & 6.27 & 5.19 & 5.73 & -0.36 & 1.19 \\
\hline Male (yes=1) & 2.81 & 3.27 & 3.04 & 0.23 & 0.95 \\
\hline Age $15-30($ yes=1) & 11.95 & 18.24 & 13.52 & 5.93 & 1.77 \\
\hline Age $31-45($ yes $=1)$ & 10.45 & 13.05 & 8.45 & 5.44 & 4.48 \\
\hline Age 46-55 (yes=1) & 1.90 & 2.15 & 0.30 & 1.94 & 1.71 \\
\hline Over age $65($ yes $=1)$ & 2.19 & 3.43 & 5.89 & -3.30 & 0.68 \\
\hline Hispanic $($ yes=1) & 0.03 & 3.93 & 4.54 & -0.73 & -4.40 \\
\hline Non-Hispanic Black (yes=1) & 8.70 & 9.00 & 6.32 & 2.43 & 5.43 \\
\hline Household income missing (yes=1) & 17.35 & 6.86 & 7.73 & -0.35 & 18.00 \\
\hline Household income under $\$ 20,000$ (yes=1) & 5.60 & 4.30 & 5.34 & -0.76 & 1.75 \\
\hline Household income $\$ 20-39,999$ (yes=1) & 1.51 & 0.73 & 1.49 & -0.41 & 0.96 \\
\hline Household income $\$ 75,000$ plus (yes=1) & 1.18 & 1.28 & 2.07 & -0.53 & 1.78 \\
\hline Less than high school (yes=1) & 4.98 & 1.66 & 2.74 & -1.19 & 1.75 \\
\hline High school graduate $($ yes $=1$ ) & 5.57 & 2.92 & 2.82 & 0.13 & 3.86 \\
\hline Bachelor's degree (yes=1) & -5.89 & -3.65 & -3.06 & -0.64 & -4.22 \\
\hline Graduate degree $($ yes $=1$ ) & -9.59 & -5.89 & -5.25 & -0.89 & -6.57 \\
\hline Northeast (yes $=1$ ) & 3.29 & 1.45 & 0.50 & 0.95 & 1.98 \\
\hline South (yes=1) & 5.16 & 5.48 & 5.54 & 0.13 & 1.74 \\
\hline West (yes $=1$ ) & 2.87 & 1.33 & 2.60 & -0.97 & 0.56 \\
\hline No telephone in household (yes=1) & 11.12 & 20.91 & 23.16 & -2.45 & -9.62 \\
\hline
\end{tabular}

Note: Changes in predicted rates associated with having versus not having the indicated characteristic are evaluated at the overall rate for the full sample, based on the logistic regression models described in the text. Figures shown in bold are statistically significant. 
Table 4: Effects of Alternative Weights on Estimates of Time Devoted to Different Activities, 2004 American Time Use Survey (average hours/day)

Weight Used for Estimates

\begin{tabular}{lccc}
\cline { 2 - 4 } Activity & $\begin{array}{c}\text { ATUS Base } \\
\text { Weight }\end{array}$ & $\begin{array}{c}\text { ATUS Final } \\
\text { Weight }\end{array}$ & $\begin{array}{c}\text { Weight Based on } \\
\text { Table 3 Model }\end{array}$ \\
\hline Personal care & & & \\
Sleep & 9.26 & 9.33 & 9.33 \\
Household activities & 8.49 & 8.56 & 8.55 \\
Housework & 1.95 & 1.82 & 1.87 \\
Food preparation & 0.63 & 0.59 & 0.61 \\
Interior maintenance & 0.55 & 0.51 & 0.53 \\
Exterior maintenance & 0.12 & 0.11 & 0.11 \\
Lawn, garden and houseplants & 0.07 & 0.06 & 0.06 \\
Caring for household members & 0.21 & 0.19 & 0.19 \\
Caring for nonhousehold members & 0.48 & 0.48 & 0.47 \\
Work and related activites & 0.19 & 0.19 & 0.19 \\
Work & 3.29 & 3.37 & 3.28 \\
Education & 3.25 & 3.31 & 3.23 \\
Consumer purchases & 0.40 & 0.46 & 0.43 \\
Professional and personal services & 0.43 & 0.41 & 0.41 \\
Household services & 0.10 & 0.09 & 0.10 \\
Government services and civic activities & 0.02 & 0.02 & 0.02 \\
Eating and drinking & 0.01 & 0.01 & 0.01 \\
Leisure activities & 1.15 & 1.11 & 1.12 \\
Socializing & 4.62 & 4.62 & 4.71 \\
Attending and hosting social events & 0.64 & 0.65 & 0.66 \\
Relaxing & 0.10 & 0.10 & 0.10 \\
$\quad$ Watching television & 3.76 & 3.77 & 3.84 \\
Arts and entertainment & 2.59 & 2.64 & 2.69 \\
Sports and exercise & 0.11 & 0.11 & 0.11 \\
Religious activities & 0.32 & 0.33 & 0.31 \\
Volunteer activities & 0.12 & 0.12 & 0.12 \\
Telephone calls & 0.16 & 0.15 & 0.15 \\
Travel & 0.12 & 0.12 & 0.27 \\
Commuting to work & 1.26 & 1.26 & \\
\hline
\end{tabular}


Appendix A: Concordance Between BLS and Own Case Disposition Codes, 2004 American Time Use Survey

\begin{tabular}{|c|c|c|c|c|}
\hline \multirow[b]{2}{*}{ Description } & \multicolumn{2}{|c|}{ BLS Case Disposition Codes } & \multirow[b]{2}{*}{$\begin{array}{c}\text { Own Case } \\
\text { Disposition Codes }\end{array}$} & \multirow[b]{2}{*}{ Number of Cases } \\
\hline & Detailed & Aggregated & & \\
\hline Completed interview & 1 & $\mathrm{C}$ & $\mathrm{C}$ & 13,886 \\
\hline Not eligible: Designated person not household member & 15 & NE & NE & 3 \\
\hline Not eligible: Designated person moved out & 17 & NE & $\mathrm{NC}-1$ & 1,284 \\
\hline Other: Designated person absent, ill, or hospitalized & 18 & $\mathrm{O}$ & $\mathrm{NC}-1$ & 1,611 \\
\hline Unknown eligibility: Unpublished or non-listed number & 22 & UE & NC-2 & 1,623 \\
\hline Unknown eligibility: Incorrect phone number & 23 & UE & NC-2 & 137 \\
\hline Not eligible: Designated person in Armed Forces & 24 & NE & $\mathrm{NE}$ & 6 \\
\hline Unknown eligibility: Privacy detector & 27 & UE & NC-2 & - \\
\hline Other: Non-interview & 29 & $\mathrm{O}$ & $\mathrm{O}$ & - \\
\hline Not eligible: Miscellaneous & 100 & $\mathrm{NE}$ & $\mathrm{NE}$ & 33 \\
\hline Refusal: By individual & 111 & $\mathrm{R}$ & $\mathrm{R}$ & 3,145 \\
\hline Refusal: By parent/guardian/gatekeeper & 112 & $\mathrm{R}$ & $\mathrm{R}$ & 742 \\
\hline Unknown eligibility: Unproductive call counter & 113 & UE & NC-2 & 103 \\
\hline Refusal: Pre-refusal based on explicit refusal or hostile break off & 116 & $\mathrm{R}$ & $\mathrm{R}$ & \\
\hline Noncontact: Incomplete callbacks, unable to contact or call back & 118 & $\mathrm{NC}$ & NC-3 & \\
\hline Noncontact:- Temnorarilv unavailable absent ill hosnitalization & 1 & $\Lambda$ & $\Lambda$ & 1,193 \\
\hline 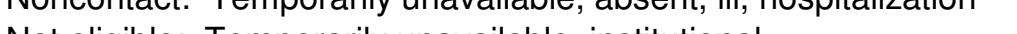 & 119 & Ne & INC-3 & 1 \\
\hline Not eligible: Temporarily unavailable, institutional & 120 & NE & NE & 56 \\
\hline Other: Unresolved language barrier & 121 & $\mathrm{O}$ & O & 2 \\
\hline Unknown eligibility: Privacy detectors & 123 & UE & NC-2 & 301 \\
\hline Noncontact: Never contacted, confirmed number & 124 & NC & NC-3 & 633 \\
\hline Unknown eligibility: Never contacted, unconfirmed number & 125 & UE & NC-2 & 15 \\
\hline
\end{tabular}


Appendix A: Concordance Between BLS and Own Case Disposition Codes, 2004 American Time Use Survey (continued)

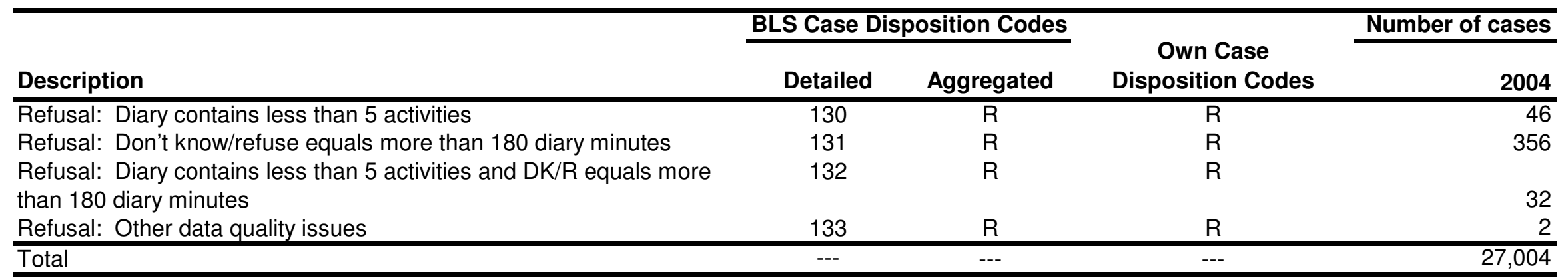

Note: The following abbreviations are used for the case disposition codes:

$\mathrm{C}=$ Complete (including sufficient partial interviews)

$\mathrm{NC}=$ Noncontact

$\mathrm{R}=$ Refusal

$\mathrm{O}=$ Other non-interview

UE=Unknown eligibility

$\mathrm{NE}=$ Not eligible 


\section{Appendix B: Creation of Explanatory Variables Used in Analyzing ATUS Nonresponse}

Code Label Comment

Respondent's Marital Status (MARSTAT)

1 Married to householder PEMARITL=1, PERRP $=1$ or $P E R R P=3$, spouse is present in the data set

3 Widowed

PEMARITL $=3$

4 Divorced

PEMARITL $=4$

5 Separated

PEMARITL=5, or respondent is married with no spouse present in the data set,

6 Never married or respondent is married to someone other than the householder

Respondent's hours worked (HOURS)

-1 NILF or unemployed

PEHRUSLT $=-1$

2 Less than $35 \mathrm{hrs} / \mathrm{wk}$

PEHRUSLT $<35$

3 35-44 hrs/wk

445 or more hrs/wk

PEHRUSLT $>=35$ and PEHRUSLT $<=44$

5 Hours vary

PEHRUSLT $>=45$

PEHRUSLT $=-4$

Spouse hours worked (SPHRSC)

-2 Labor force status unknown

-1 NILF or unemployed

No information for spouse PEHRUSLT or spouse PEMLR

MARSTAT $=1$ and spouse PEHRUSLT $=-1$

2 Less than $35 \mathrm{hrs} / \mathrm{wk}$

MARSTAT $=1$ and spouse PEHRUSLT $<35$

3 35-44 hrs/wk

MARSTAT $=1$ and spouse PEHRUSLT $>=35$ and spouse PEHRUSLT $<=44$

445 or more hrs/wk

MARSTAT $=1$ and spouse PEHRUSLT $>=45$

5 Hours vary

999 No spouse

MARSTAT $=1$ and spouse PEHRUSLT $=-4$

MARSTAT ne 1

Presence of children age 5 and under (AGE5C)

0 No

Counted all persons with age $<6$ in household, then dichotomized

1 Yes

Presence of children age 6-17 (AGE617C)

0 No

Counted all persons with age 6-17 in household, then dichotomized

1 Yes

Housing tenure (HTENURE)

1 Own

2 Rent

3 Not in universe

Urbanicity (URBAN)

1 Central city

2 Balance on MSA

3 Metro-Other

4 Non-metropolitan

5 Not identified
HETENURE $=1$

HETENURE=2 (rented for cash) or HETENURE=3 (occupied without payment of cash rent)

HETENURE=-1 (included with reference category [owners] in regression models)

Presence of other adults not related to householder (NORELC)

0 No

1 Yes
GEMETSTA $=1$ and $\mathrm{GTMSAST}=1$ or $\mathrm{GTMETSTA}=1$ and $\mathrm{GTCBSAST}=1$ GEMETSTA $=1$ and $\mathrm{GTMSAST}=2$ or $\mathrm{GTMETSTA}=1$ and $\mathrm{GTCBSAST}=2$ GEMETSTA $=1$ and $\mathrm{GTMSAST}=4$ or $\mathrm{GTMETSTA}=1$ and $\mathrm{GTCBSAST}=4$ GEMETSTA $=2$ and $\mathrm{GTMSAST}=3$ or $\mathrm{GTMETSTA}=2$ and $\mathrm{GTCBSAST}=3$ GEMETSTA $=3$ and $\mathrm{GTMSAST}=4$ or $\mathrm{GTMETSTA}=3$ and $\mathrm{GTCBSAST}=4$

PERRP and PRTAGE used to count the number of adults living in the household who are unrelated to the householder, then dichotomized 
Appendix B: Creation of Explanatory Variables Used in Analyzing ATUS Nonresponse (continued)

\begin{tabular}{|c|c|}
\hline Code Label & Comment \\
\hline \multicolumn{2}{|c|}{ Presence of other adults related to householder (RELC) } \\
\hline 0 No & $\begin{array}{l}\text { PERRP and PRTAGE used to count the number of adults living in the } \\
\text { household who are related to the householder, then dichotomized }\end{array}$ \\
\hline \multicolumn{2}{|r|}{ 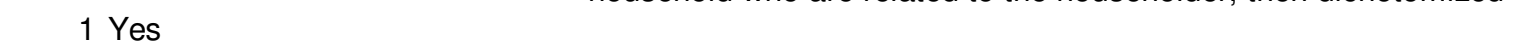 } \\
\hline \multicolumn{2}{|l|}{ Respondent's sex (PESEX) } \\
\hline 0 Female & PESEX $=2$ \\
\hline 1 Male & PESEX $=1$ \\
\hline \multicolumn{2}{|l|}{ Respondent's age (RAGE) } \\
\hline 130 and under & PRTAGE $<=30$ \\
\hline $231-45$ & PRTAGE $>=31$ and PRTAGE $<=45$ \\
\hline $346-55$ & PRTAGE $>=46$ and PRTAGE $<=55$ \\
\hline $456-65$ & PRTAGE $>=56$ and PRTAGE $<=65$ \\
\hline $5>65$ & PRTAGE>65 \\
\hline \multicolumn{2}{|c|}{ Respondent's race/ethnicity (RACE) } \\
\hline 1 Hispanic & PEHSPNON $=1$ \\
\hline 2 Non-hispanic black & PEHSPNON ne 1 and PTDTRACE $=2$ \\
\hline 3 Other & PEHSPNON ne 1 and PTDTRACE ne 2 \\
\hline \multicolumn{2}{|l|}{ Household income (FAMINC) } \\
\hline-1 Missing & HUFAMINC=-1 \\
\hline 1 Less than $\$ 20,000$ & HUFAMINC $>=1$ and $\mathrm{HUFAMINC}<=6$ \\
\hline $2 \$ 20,000-\$ 39,999$ & HUFAMINC $>=7$ and HUFAMINC $<=10$ \\
\hline $3 \$ 40,000-\$ 74,999$ & HUFAMINC $>=11$ and HUFAMINC $<=13$ \\
\hline $4 \$ 75,000$ or more & HUFAMINC $>13$ \\
\hline \multicolumn{2}{|l|}{ Education (ED) } \\
\hline 1 Less than high school & PEEDUCA $<=38$ \\
\hline 2 High school & PEEDUCA=39 \\
\hline 3 Some college & PEEDUCA $>=40$ and PEEDUCA $<=42$ \\
\hline 4 Bachelor's degree & PEEDUCA $=43$ \\
\hline 5 Graduate degree & PEEDUCA $>=44$ \\
\hline \multicolumn{2}{|l|}{ Region (GEREG) } \\
\hline \multicolumn{2}{|l|}{1 Northeast } \\
\hline \multicolumn{2}{|l|}{2 Midwest } \\
\hline \multicolumn{2}{|l|}{3 South } \\
\hline \multicolumn{2}{|l|}{4 West } \\
\hline Telephone status (HETELHHD & \\
\hline 1 Yes & \\
\hline 2 No & \\
\hline
\end{tabular}

